\title{
A riboflavin tracer method for assessment of medication compliance in children
}

\author{
PATRICIA A. CLUSS and LEONARD H. EPSTEIN \\ University of Pittsburgh, Pittsburgh, Pennsylvania
}

\begin{abstract}
A series of studies was implemented to adapt a riboflavin tracer method of medication compliance detection that could be employed easily and accurately by parents in a behavioral program aimed at targeting and improving compliance in children. Results of these studies indicated that, with minimal training in the use of an inexpensive fluorescent "black light," adults could reliably detect the presence of riboflavin (vitamin $B_{2}$ ) in the urine of children who had ingested $10 \mathrm{mg}$ of the vitamin at bedtime. Implications for the use of this technique in a home-based behavioral program that targets medication compliance are discussed.
\end{abstract}

It is well established that adherence to medication regimens among patients requiring long-term treatment is poor. Sackett and Snow (1979) found the mean compliance rate of patients on long-term medication regimens to be approximately $54 \%$. Although many researchers have attempted to target and modify compliance problems, a major difficulty in this research has been the lack of accurate compliance assessment methods (Epstein \& Cluss, 1982). Self-report data (e.g., Bergman \& Werner, 1963), compliance data inferred from therapeutic outcome (e.g., The Coronary Drug Project, 1980), and estimates of compliance by physicians (e.g., Caron \& Roth, 1971) are of questionable validity. The accuracy of pill and bottle counts and serum and urine assays depends upon factors such as drug half-life, absorption and excretion patterns of the drug, and patients' knowledge of when blood or urine samples or empty bottles will be requested (Epstein \& Cluss, 1982).

Tracer "tags" or "markers" added to medications may provide the best currently available method of day-to-day compliance testing (Epstein \& Cluss, 1982). With this technique, a tracer substance such as riboflavin (vitamin $B_{2}$ ) (Berry, Ross, Huempfner, \& Deuschle, 1962; VA Cooperative Study Group, 1970), phenosulfonphthalein (Ryan, Carver, \& Haller, 1962), or phenazopyridine (Epstein \& Masek, 1978) is added to doses of the patient's medication, and later the patient or

This research was conducted in part for fulfillment of the requirements for the PhD in psychology at the University of Pittsburgh (Dr. Cluss). The authors wish to thank the following for their support of this project: Drs. Fireman, Friday, Miller, Landay, Murphey, and Caliguire; Kathy Nicholas, Patty Hoffman, and Tom DelFaver; and Key Pharmaceuticals, Inc. Correspondence concerning this article may be addressed to Patricia A. Cluss, PhD, Psychophysiological Studies, Western Psychiatric Institute and Clinic, 3811 O'Hara Street, Pittsburgh, PA 15213. doctor tests for the presence of the easily detectable tracer substance in the urine.

In an ongoing research program (Epstein, Beck, Figueroa, Farkas, Kazdin, Daneman, Becker, 1981; Daneman, Epstein, Siminerio, Beck, Farkas, Figueroa, Becker, \& Drash, 1982), we have attempted to develop compliance assessment methods that can be employed by parents at home as part of a behavioral treatment package that focuses on improving compliance in children with chronic disease. The home monitoring of medicine compliance facilitates parental decisions about when to provide positive reinforcement for compliance or punishment for noncompliance.

In the present studies, an attempt was made to adapt the use of a riboflavin tracer for the home assessment of asthmatic children on theophylline. Riboflavin (vita$\min B_{2}$ ) excreted in the urine fluoresces when placed under ultraviolet light and has been used as a tracer substance in several studies (e.g., Berry et al., 1962; VA Cooperative Study Group, 1970) as a method of compliance assessment. This vitamin meets Porter's (1969) requirements that a tracer substance be nontoxic (pharmacologically and chemically inert), unaffected by the physical and chemical properties of the urine, and freely excreted and is, therefore, an excellent candidate for use as a marker in medication. Vitamin $\mathbf{B}_{2}$ is water soluble, and thus any amount of the vitamin in excess of what the body needs is excreted with no ill effects. As a vitamin, however, it is present in many foods and in various multiple-vitamin preparations, which could result in false positives for compliance.

Three studies were designed to determine the applicability of home monitoring methods for use in a homebased behavioral program targeting child medication compliance. We hoped to develop a riboflavin tracer that could be added to children's prescribed medication for simple and accurate assessment of pill-taking behavior. 


\section{STUDY 1}

\section{Method}

Subjects. The subjects were six healthy adult volunteers (four women, two men), ages 30 to 45 years.

Procedure. Since the goal of this series of studies was to determine whether lay adults could detect fluorescence in the urine accurately, Study 1 was designed to test whether relatively untrained adults could detect varying amounts of riboflavin in their urine with inexpensive equipment used at home. In addition, the question of whether the amount of vitamin $B_{2}$ excreted after consuming a normal diet would cause urine to fluoresce was explored.

On Day 1 of this study, the subjects ate a normal diet and collected a urine sample at bedtime and at the first void the next morning. On Days 2 and 3, a " $\mathbf{B}_{\mathbf{2}}$-fast" was initiated, in which the subjects consumed as few as possible of food items high in riboflavin. They also discontinued taking any vitamin supplement that contained vitamin $B_{2}$ or the B-complex vitamins.

During Days 4 through 10 , the subjects ingested capsules containing various amounts of riboflavin and/or a similarly colored placebo at bedtime and collected first-void urine samples. Doses of vitamin $\mathbf{B}_{2}$ were set randomly at $50,0,25,2.5,5,10$, and $25 \mathrm{mg}$, respectively; the subjects were blind to daily dosage levels.

Each subject was given an inexpensive fluorescent "black light" purchased from Spencer Gifts, Inc. (Atlantic City, NJ), and, after having been given minimal training in assessing fluorescence with the light, determined which of their urine samples were fluorescent and which were not. The subjects refrigerated each sample and returned it to the experimenter within $24 \mathrm{~h}$ for verification of fluorescence/nonfluorescence with a shortwave ultraviolet light (Model SL2537, Ultraviolet Products, Inc., South Pasadena, CA; 110 Volts, $9 \mathrm{~W}$ ).

\section{Results}

Due to spillage, etc., 9 of 42 potential specimens were unavailable for analysis. The subjects were correct in determining fluorescence/nonfluorescence of urine in 24 of 33 judgments ( $73 \%$ accuracy). Significant results were shown when the observed number of correct and incorrect judgments was compared with the number expected to occur by chance $\left(\chi_{1}^{2}=6.82, \mathrm{p}<.025\right)$. Accuracy was $83 \%$ when samples collected after consuming larger amounts of vitamin $B_{2}(\geq 10 \mathrm{mg}$ ) were considered alone in the analysis, and was only $54 \%$ when smaller amounts ( $\leq 5 \mathrm{mg}$ ) had been ingested.

The subjects ingested $0 \mathrm{mg}$ of riboflavin the day after they had ingested $50 \mathrm{mg}$ of the vitamin. Urine samples should have been nonfluorescent after consumption of placebo only, but $80 \%$ did appear to be fluorescent, indicating the probability of some "spillover" from the $50-\mathrm{mg}$ dose into the following day's urine.

\section{STUDY 2}

\section{Method}

Subjects. Six healthy children, ages 7 to 12 years, were recruited. None was taking a daily vitamin supplement containing the B-complex vitamins.

Procedure. This study was designed to develop the riboflavin tracer technique for use with children and parents by assessing whether the vitamin $B_{2}$ in children's normal diets would cause urine to fluoresce and whether adults could accurately detect fluorescence in the urine after the children had ingested $10 \mathrm{mg}$ of riboflavin. The subjects ate their usual diets and collected one bedtime urine sample immediately before ingesting a capsule containing $10 \mathrm{mg}$ of vitamin $\mathrm{B}_{2}$. The next morning, first-void urine specimens were collected; these were returned to the experimenter within $24 \mathrm{~h}$.
One bedtime sample was unavailable, leaving 11 urine specimens that were judged by nine lay adults who had received the same minimal training in the black-light method of fluorescence detection given to the subjects in Study 1

\section{Results}

All five samples collected at bedtime after consumption of a normal diet were nonfluorescent; all six samples taken the morning after ingestion of $10 \mathrm{mg}$ of riboflavin were fluorescent. Of 99 lay adult judgments, 87 were correct and 12 were incorrect ( $88 \%$ accuracy) $\left(\chi_{1}^{2}=56.82, \mathrm{p}<.001\right)$.

An additional chi-square test was performed, using Yates's correction, to determine whether urine sample fluorescence/nonfluorescence and accuracy of judgment were independent. Results indicated that Type I errors (false negatives) were significantly more likely than Type II errors (false positives) $\left(\chi_{1}^{2}=5.98, \mathrm{p}<.025\right)$.

\section{STUDY 3}

\section{Method}

Subjects. Five of the six Study 2 children participated in Study 3. None was taking vitamin supplements, and all consumed their regular diets.

Procedure. The purpose of this study was to determine rate of fluorescence "spillover" from one 24 -h period to the next in children taking $10 \mathrm{mg}$ of vitamin $\mathbf{B}_{2}$. The subjects ingested $10 \mathrm{mg}$ of riboflavin at bedtime on Days 1 and 3 of the study, took nothing on Days 2 and 4, and collected first-void samples following each of the 4 days.

\section{Results}

Of the 19 specimens returned, all but one sample were fluorescent the morning after vitamin $\mathbf{B}_{2}$ ingestion and nonfluorescent the morning after no vitamin $\mathrm{B}_{2}$ had been ingested, as determined by the experimenter. The one "incorrect"' sample was still minimally fluorescent when no vitamin had been taken the night before.

To further test the accuracy of adult judgments of vitamin $B_{2}$ presence, 10 lay adults judged fluorescence of 18 samples (the "spillover" sample was excluded). Of 180 judgments, 169 were correct ( $94 \%$ accuracy), a highly significant finding $\left(\chi_{1}^{2}=69.34, \mathrm{p}<.001\right)$. In this sample, fluorescence/nonfluorescence of urine samples was unrelated to accuracy of judgment $\left(\chi_{1}^{2}=0.12, \mathrm{p}>.05\right)$. Results also showed that, in Studies 2 and 3, in which dosage levels of vitamin $\mathbf{B}_{\mathbf{2}}$ were constant, lay adult raters using an inexpensive black light showed $89 \%$ agreement with the determinations of the experimenter, who had used the shortwave ultraviolet lamp.

\section{DISCUSSION}

These three studies show that relatively untrained adults can, using a black light, accurately detect fluorescence in urine samples of subjects who have ingested riboflavin at bedtime. Fluorescence detection for adult urine was most accurate with larger doses of the vitamin, although a 50-mg dose resulted in "spillover" of urine fluorescence into a sample taken during the next $24-\mathrm{h}$ period. A normal diet did not contain enough vitamin $B_{2}$ to cause 
detectable fluorescence in the urine of adults or children.

Studies 2 and 3 demonstrated that lay adults can accurately detect the presence of fluorescence in the urine of children who have ingested a 10-mg bedtime dose of riboflavin. Results of Study 3 showed that "spillover" of fluorescence into the following day's urine occurred in only $5 \%$ of specimens. This, in conjunction with the high accuracy of adult judgments $(94 \%)$, demonstrates that ingestion of $10 \mathrm{mg}$ of vitamin $\mathrm{B}_{2}$ by children is sufficient to enable easy detection in the urine, but also avoids "spillover" in the great percentage of cases. We did not attempt to develop riboflavin doses that were based on subjects' weights, a correction that should improve the detection of compliance and minimize "spillover," although additional medication preparation would be required.

This series of studies was an initial step in the process of developing and validating an accurate tracer method for use in compliance assessment. The present data show that riboflavin is an effective tracer substance that can be detected reliably in the urine after bedtime ingestion. The next step, which we also have completed and have reported elsewhere (Cluss, Epstein, Galvis, Fireman, \& Friday, 1984), was to validate the method as a useful assessment of pill-taking behavior in a clinical sample. We tested a sample of asthmatic children over a 2-week period to determine compliance to prescribed theophylline regimens. Compliance was assessed by the method described in the present paper, with $10 \mathrm{mg}$ of riboflavin added to bedtime theophylline capsules. Noncompliant subjects reported more wheezing days, showed more variable lung functioning, recorded lower peak flow rates, and were significantly more likely to have been wheezing on the day of an office visit than their more compliant peers. These data, then, demonstrate the validity of our riboflavin tracer and the black-light method of fluorescence assessment for discriminating between groups of compliant and noncompliant children in a manner that is both statistically and clinically relevant.

One extension of these results would be the development of a home-based behavioral compliance program for children with chronic disease. Such a procedure would allow parents trained in this method to assess children's compliance with a medication regimen on a daily or weekly basis and to reinforce relatively immediately appropriate medication-taking behavior. An experimenter would verify parents' assessments at a later time. The method could also be useful as a measure of longterm compliance, with urine being assessed on a more periodic basis.
This safe, easy-to-use tracer method and black-light technique for assessing compliance has many advantages over other more traditional compliance detection methods, especially when daily adherence patterns are of concern. Further refinement of the technique is necessary to determine the feasibility and practicality of its use in long-term treatment studies.

\section{REFERENCES}

Bergman, A. B., Werner, R. T. (1963). Failure of children to receive penicillin by mouth. New England Journal of Medicine, 268 , 1334-1338.

Berry, D., Ross, A., Huempfner, H., \& Deuschle, K. (1962). Selfmedication behavior as measured by urine chemical tests in domiciliary tuberculosis patients. American Review of Respiratory Disease, 86, 1-7.

CARON, H. S., \& RoTH, H. P. (1971). Objective assessment of cooperation with ulcer diet: Relation to antacid intake and to assigned physician. American Journal of Medical Science, 261, 61-66.

Cluss, P., Epstein, L., Galvis, S., Fireman, P., Friday, G. (1984). Effect of compliance on chronic asthmatic children. Journal of Consulting and Clinical Psychology, 52, 909-910.

Daneman, D., Epstein, L. H., Siminerio, L., Beck, S., Farkas, G., FigueroA, J., Becker, D., \& Drash, A. (1982). The effects of enhanced conventional therapy on metabolic control in children with insulin dependent diabetes mellitus. Diabetes Care, 5, 472-478.

Epstein, L., Beck, S., Figueroa, J., Farkas, G., Kazdin, A., DaneMAN, D., \& BECKER, D. (1981). The effects of targeting improvements in urine glucose on metabolic control in children with insulindependent diabetes. Joumal of Applied Behavior Analysis, 14, 365-375.

EpsteIn, L. H., \& Cluss, P. A. (1982). A behavioral medicine perspective on adherence to long-term medical regimens. Journal of Consulting and Clinical Psychology, 50, 950-971.

EPSTEIN, L. H., \& MASEK, B. J. (1978). Behavioral control of medicine compliance. Journal of Applied Behavior Analysis, 11, 1-10.

Porter, A. M. (1969). Drug-defaulting in a general practice. British Medical Journal, 1, 218-222.

Ryan, W. L., Carver, M. J., \& Haller, J. (1962). Phenosulfonphthalein as an index of drug ingestion. American Journal of Pharmacy, 134, 168-171.

SACKeTt, D. L., \& SNOW, J. C. (1979). The magnitude of compliance and noncompliance. In R. B. Haynes, D. W. Taylor, \& D. L. Hackett (Eds.), Compliance in health care (pp. 11-22). Baltimore, MD: Johns Hopkins Press.

The Coronary Drug Project Research Group (1980). Influence of adherence to treatment and response of cholesterol on mortality in the Coronary Drug Project. New England Journal of Medicine, 303, 1038-1041.

Veterans administration Cooperative Study Group on ANTIHYPERTENSIVE AGENTS. (1970). Effects of treatment on mortality in hypertension: Results in patients with diastolic blood pressure averaging 90 through $114 \mathrm{mmHg}$. Journal of the American Medical Association, $213,1143-1152$.

(Manuscript received October 10, 1983; revision accepted for publication October 27, 1984.) 